\title{
Using SCAMPER Strategy for Developing Third Year English Majors' Creative Writing Skills
}

\author{
Al-Shimaa Mokhtar Sayed*, Kawther I. M. Kotb, Gamal Mohamed shehata \\ Department of English, Faculty of Education, Minia University, 61519 Minia, Egypt \\ * Correspondence: shimaamok2010@gmail.com; Tel: +201093327233; Fax: +20 862347767
}

\section{Article information}

Received: 19 February 2020

Revised: 25 March 2020

Accepted: 26 March 2020

\section{Key words}

SCAMPER

Creative writing skills

Strategy

\begin{abstract}
The present study tried to investigate the effect of using the strategy of Substituting, Combining, Adapting, Putting it in other uses, Eliminating, Revising (SCAMPER) on developing third-year English majors' creative writing skills. The study used one group (pre-test and post-test design). Instruments of the study were: a program based on SCAMPER strategy, a creative writing skills test, and a performance rubric for evaluating students' creative writing. Participants of the study were ninety students from third-year English majors, Faculty of Education, Minia University. They were taught the program based on SCAMPER. The results of the study reveal that there was a significant statistical difference favoring the post-performance of the creative writing skills test. It was found that SCAMPER strategy developed students' creative writing skills. Findings were discussed. The researcher recommended that EFL teachers at the Ministry of Education should be trained to use SCAMPER in teaching all the language skills. Suggestions for further research were also presented.
\end{abstract}

\section{Introduction}

Learning English as a foreign language (EFL) is not an easy task; it requires mastering the four language skills: listening, speaking, reading and writing. By mastering them we will be better communicators. Writing in EFL is the most difficult main skill and the last to be mastered even to natives. Thus the majority of students consider writing a paragraph or an essay a difficult task [1].

[2] stated that writing is considered one of the highly complex mental processes; writing is a continuing process of discovering how to find the most effective language for communicating one's thoughts and feelings. It can be challenging, whether the writing is in one's native language or in a second language while [3] asserts that students may feel threatened by a blank piece of paper and a request to write a story about a given topic. The act of writing not only reflects our thinking but also helps us to create new ideas.

With creative writing students can gain a greater sense of community and creativity when they write with their peers, and they can also enhance their introspective skills while writing by themselves. Having unique creative writing activities can make the difference between a good and a great class. Creative writing is very important because it helps students to enter the creative life and think out of the box [4]. Creative writing provides an alternative to traditional ways of discussing texts [5].

[6] Mentioned that originality, flexibility, and fluency are the main skills of creative writing:

- Originality is to generate new and unusual ideas.
- Flexibility is to produce different ideas.

- Fluency is the ability to produce a large number of ideas quickly.

Many new strategies have been developed to enhance the concept of creativity so the learner could be able to think creatively to solve the problems. One of these strategies is SCAMPER in which students will:
1. S: substitute.
2. C: combine.
3. A: adapt.
4. M: modify.
5. P: put to use.
6. E: eliminate.
7. R: reverse.

\section{Context of the problem}

To document the problem of the present study, the researcher developed a needs assessment questionnaire for using a program based on SCAMPER strategy for developing creative writing skills, and a questionnaire for identifying English majors' main and sub-skills of creative Writing validated by a panel of teaching English as a foreign language (TEFL) staff members.

1- The questionnaire was administered to 50 students from third year English Majors, Faculty of Education, Minia University .The purpose of this questionnaire is to assess their needs for the program and to find out what English majors know about SCAMPER and its role in developing creative writing skills. 
The results of the questionnaire showed that they need to use a program based on SCAMPER strategy to help them to write creatively.

2- A questionnaire for identifying English majors' main skills and sub-skills of creative writing needed by third year English majors, a suggested list of the main and sub-skills of creative writing administered on a panel of TEFL staff members. On analyzing the obtained data showed that creative writing skills are needed most by the study group.

\section{Statement of the problem}

The present study aimed at using the SCAMPER strategy to design a program that could help students to write creatively.

\section{Objective of the Study}

The current study attempted to achieve the following objective:

1- Using a program based on SCAMPER strategy for developing third year English majors' creative writing skills.

\section{Question of the study}

The present study attempted to find an answer to the following question:

What was the effectiveness of using a program based on SCAMPER strategy for developing third year English majors' creative writing skills?

\section{Hypothesis of the study}

There was no significant statistical difference between mean scores obtained by participants of the study group on the post test of creative writing skills.

\section{Significance of the study}

\section{The present study would offer:}

1- A program based on SCAMPER strategy that could be used by EFL instructors in teaching English courses at the Faculty of Education. This program was needed because it was not available as part of any of the courses of the teacher preparation program.

2- A Test of Creative Writing skills.

3- A Rubric for evaluating Students' Performance in Creative Writing.

\section{Literature Review}

\subsection{SCAMPER}

\subsubsection{SCAMPER as a Teaching Strategy}

SCAMPER strategy is based on the idea that new things are a modification of what already exists. It is considered a technique, a strategy or a collection of activities for creative problem-solving. The strategy was further first developed by
Bob Eberle and noted in his book, SCAMPER: Games for Imagination Development. Eberle states that much as the word SCAMPER suggests "running playfully about as a child", the strategy SCAMPER may also evoke the need "to run playfully about in one's mind in search of ideas" [7] .

SCAMPER strategy offers an organized, systematic and practical way to stimulate imagination and originality while scaffolding students' creative thinking for independent use on other tasks and assignments [8].

[9] stated that SCAMPER is an acronym standing for the following principles:

1. "S" Substitute: Substitution is a trial-and-error method where you can try things out, see if it works, then try something different.

2. "C" Combine: Combining involves synthesis, the process of combining previous ideas or knowledge with the existing ideas to create something new.

3. "A" Adapt: Thinking about what is already known about the problem and how others are solving it taking into consideration the process others are using.

4. "M" Modify, magnify or minify: When you modify and alter something, you reflect on what is needed to make it better, greater, simpler, or even more complicated.

5. "P" Put to other uses: Considering possible ways and situations can be used other than the original one.

6. "E" Eliminate or elaborate: To remove or omit part or all of a particular quality to add more details.

7. "R" Reverse or Rearrange: When using reverse, the focus is on the opposite meaning. When using rearrange, the focus is on how the change of order would affect the target or challenge.

\subsubsection{How to use SCAMPER?}

[10] state that when using this strategy in the classroom, it will be helpful for the teacher to:

1. Review the SCAMPER acronym with its associated activities to help students to think and react differently.

[9] Identified two steps when using SCAMPER in the classroom:

1- Defining the goal:

Presenting the idea, process or problem that we want to change.

2- Using the SCAMPER strategy:

1. Direct students to use principles of SCAMPER using activities based on it.

2. Group members call out their answers for discussion. Any response to the SCAMPER strategy is welcomed no matter how non-logical it is.

Many researchers investigated the use of SCAMPER in developing Creativity and Creative Thinking such as [11]who conducted a study to investigate the effectiveness of the SCAMPER strategy or the free production of ideas in the development of creative thinking skills of the students / teacher at Sohag Faculty of Education and improves their attitudes 
towards creativity. Participants of the study were 60 students first year Faculty of Education Sohag University. They were divided into two groups (treatment group and non-treatment one). The instruments of the study included a creative thinking test and an attitude scale towards creativity, the results of the study revealed that there were highly significant differences between the treatment and non-treatment groups in the postperformance.

[10] Conducted a study entitled "Y Using SCAMPER-based activities in teaching story to enhance EFL primary stage pupils' speaking skills (An Exploratory Study), the study adopted the quasi-experimental design that involved two groups; treatment and non-treatment groups. The participants of the study were sixty pupils randomly selected from six grades Fakhr Dakahlia Language School in Mansoura city, thirty pupils represented the non-treatment group and thirty pupils represented the treatment one. The study was delimited to creative speaking skills. To fulfill the purpose of the study the researcher designed and used two instruments; a pre-post test for measuring the pupils' creative speaking skills and a rubric. SCAMPER-based activities were administered to the treatment group for eight weeks, whereas the non-treatment group was taught using the regular way of instruction. The results of the study indicated that there was a statistically significant difference between the mean scores of the treatment and non-treatment group in the post administration of the creative speaking skills test favoring the treatment group. This revealed that using SCAMPER strategy led to a significant improvement in developing pupils' creative speaking skills. Therefore, it was recommended that the Ministry of Education should hold pieces of training for EFL teachers in using SCAMPER strategy in teaching story, in order to help their pupils develop their speaking skills.

[12] conducted a study to investigate the effect of using SCAMPER strategy on improving Jordanian female tenth grade students creative writing skills. To achieve this effect, the researcher developed a creative writing test and a teacher's guide in the light of SCAMPER strategy. The participants of the study consisted of forty seven female students at Madabba governorate in the second semester of the academic year 2015/2016, the participants were divided into two groups (treatment: twenty-two students) taught by SCAMPER strategy and (non-treatment twenty-five) taught by the traditional method, the results of the study showed that there was a significant statistical difference between mean scores obtained by the participants in all the creative writing skills, and it was due to using SCAMPER strategy, the researcher recommended using scamper strategy in teaching other language skills.

[13] also conducted a study to find out what extent the SCAMPER strategy activities could help fourth graders generate creative ideas while augmenting their inventiveness. The participants were twenty-four students from suburban Midwestern elementary school. The participants of the treatment group used SCAMPER charts with animal adaptation ideas to generate ideas to improve a product using limited materials whereas the non-treatment group used simple
SCAMPER charts to improve a product with limited materials. A rubric was designed to assess the utilization of the SCAMPER chart and students' inventiveness. Students' inventiveness scores showed a statistically significant difference favoring the treatment group.

[14] conducted a study to investigate the effectiveness of SCAMPER model in developing the creative linguistic performance of linguistically gifted pupils at the preparatory stage, the research problem was represented in the low level of productive creative language performance skills (creative speaking - creative writing) among linguistically gifted students in the preparatory stage. The study aimed at recognizing the effectiveness of SCAMPER model in developing creative language performance skills of these students. The participants were thirty linguistically gifted students in preparatory second grade. The research used one-group (pre-post research design). The results indicated the effectiveness of SCAMPER model in developing creative language performance skills (creative speaking - creative writing) of the research group students. There was statistically significant difference at the level (0.01) in favor of the post application of the creative speaking skills test and the creative writing skills one. The effect size was large for the educational content designed according to SCAMPER model.

[15] conducted a study to investigate the efficacy of some proposed activities based on SCAMPER strategy with other four strategies to develop creative thinking of English learners at the preparatory stage. The participants were seventy students from second year preparatory stage. The results of the study showed a high achievement in English language and developed learners' creative thinking.

\subsection{Creative writing}

- Simply, it is a way for students to express themselves in a new and exciting way.

- To think /write outside the box.

\subsubsection{Creative writing skills:}

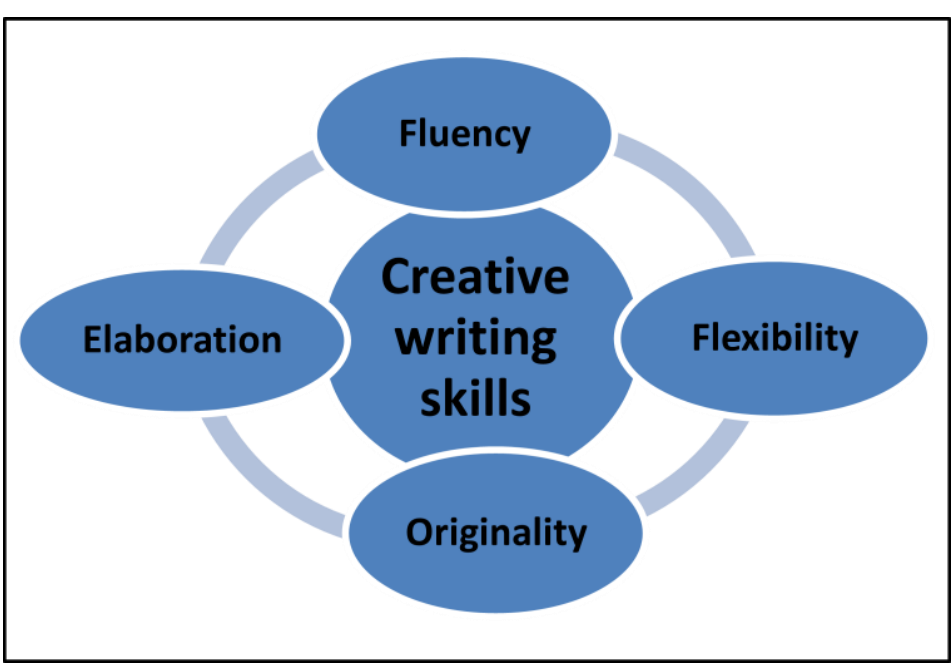

Figure 1: Creative writing skills 
Fluency is the ability to produce a large number of ideas quickly/ nonstop writing process, flexibility is to produce/ write different ideas, originality is the quality of being novel or unusual in writing, and elaboration is the ability to write with more details.

[16] defined fluency as the ability of expressing oneself in an intelligible, accurate, and perfect way without extra hesitation, otherwise, the communication will fail because listeners will lose their interest".

[17] conducted a study to investigate using a blended learning strategy to enhance official language prep school students' English creative writing skills, instruments of the study were: a list of creative writing skills, creative writing test, rubric for assessing students' performance in creative writing, and a blended learning program in creative writing, the research design was one group (pre-post research design) the participants were twenty-four from third year prep graders from Nile official school for languages in Beni Suef. The results showed that the blended learning could refresh the atmosphere of learning and increase the students' motivation, cooperation, and develop creative writing skills.

[2] Conducted a study to investigate the effect of training first year English majors of the Faculty of Education in integrating creative reading and writing skills on their performance in these skills. The participants of the study were sixty students randomly divided into two groups: a treatment group and a nontreatment one. The treatment group has been trained through a program of creative reading and writing skills using some strategies that were useful in integrating these skills. The content was based on some short stories whereas the nontreatment group was taught the same short stories through the regular way of instruction. Strategies used in implementing the program were: The Language Experience Approach, Brainstorming, Semantic Mapping, and Jigsaw. Instruments of the study were a questionnaire to determine the sub-skills of creative reading and creative writing skills, a training program in creative reading and creative writing skills, a pre post-test in creative reading - skills, and a pre post-test in creative writing skills. The statistical analysis revealed that the treatment group significantly surpassed the non-treatment one in the postperformance of both tests of creative reading skills and creative writing skills. Discussion of the findings, recommendations, and suggestions for further research were presented.

[18] designed creative writing activities to encourage students to be creative in their own writing as well as being critical and analytical of another's. The objective was to create the beginning of a story, introduce the characters and the setting, develop the action of a story, bring the story to a conclusion, read and analyze another's work. The researcher found that students, who accomplished very little during typical, structured writing time, became very involved in this type of writing.

[19] used story completion as a writing exercise to develop the students' creative writing abilities. Results showed that students could imitate the writer's work and later comment on it. Hopefully, once students were used to self-monitoring checklist, they would internalize some of the general concepts of story structure and rely less on the checklist. Results showed that story writing could develop creative writing skills.

The previous studies showed that SCAMPER strategy has been mainly used to develop Creativity, creative (writing, reading and speaking skills) and Creative Thinking Skills. In this study, SCAMPER strategy was used in teaching third year English majors to develop their creative writing skills.

\section{Materials and Method}

\subsection{Research Design}

The present study adopted the one group pre- post test research design. The study group was exposed to pre-post testing. The study group was taught using the suggested program based on SCAMPER.

\subsection{Participants of the study}

Participants were ninety students from among third year English majors - Minia University.

\subsection{Variables of the Study}

\subsubsection{Independent variable}

- The use of a program based on SCAMPER strategy.

\subsubsection{Dependent variables}

- Creative writing skills.

\subsection{Instruments of the study}

1. A needs assessment questionnaire in using a program based on SCAMPER strategy.

2. A suggested list for creative writing main skills and sub-skills.

3. The program which was based on SCAMPER strategy.

4. Test of Creative writing skills.

5. A rubric for evaluating third year English majors' level of performance in creative writing skills.

\section{Test of Creative writing skills}

\subsection{Test Validity}

\section{1- Content validity}

To determine the content validity of the test, the researcher administered it to a panel of TEFL staff members to evaluate its content validity. The majority of the panel commented that:

1- The test was considered a valuable contribution to literature.

2- The test items were well stated.

3- The test was well prepared.

4- Items were clear and varied.

5- Questions were suitable for the participants' academic level. 
2- The Internal consistency of the test was calculated in (Table 1).

Table 1: Internal Consistency of the creative writing skills Test

\begin{tabular}{ccc}
\hline Creative writing skills & Internal Consistency & Sig. \\
\hline Fluency & $0.834^{* *}$ & .000 \\
Flexibility & $0.789^{* *}$ & .000 \\
Originality & $0.873^{* *}$ & .000 \\
Elaboration & $0.944^{* *}$ & .000 \\
\hline
\end{tabular}

**significant at $(0.01)$

From the above table, it was obvious that the correlation coefficient of each dimension of the test was significant at (0.01). This indicated the validity of the test's dimensions.

\subsection{Reliability of the creative writing skills test}

To establish the reliability of the test the researcher used Alfa-Cronbach's formula. The reliability coefficient was (0.730) and this value had a statistical significance that showed the reliability of the test.

Table 2: Alfa-Cronbach's Reliability Value of the Creative writing skills Test

\begin{tabular}{cc}
\hline Alfa-Cronbach's value & N. of Items \\
\hline 0.730 & 10 \\
\hline
\end{tabular}

\section{Inter rater reliability}

To establish the reliability of the test the researcher used two raters. The first rater was the researcher herself while the second rater was another colleague with the same qualification. Pearson correlation was used.

(Table 3) illustrates that there was a highly significant correlation between the two raters.

Table 3: Correlation coefficient between the two raters on the creative writing skills test

\begin{tabular}{ccc}
\hline Raters & Internal Consistency & Sig. \\
\hline Rater 1 & $.931 * *$ & .000 \\
Rater 2 & $.876 * *$ & .000 \\
\hline
\end{tabular}

**Significant at (0.01)

\subsection{The creative writing skills Rubric}

The researcher designed a rubric for Evaluating Third Year English Major' level of performance in creative writing skills, it was also evaluated by a panel of TEFL staff members.

\section{Procedures of the study}

1. Assessing students' needs through administering a questionnaire, and a list of the main and sub-skills of creative writing skills to third year English majors and EFL instructors.

2. Designing the framework of the program and having it evaluated by a panel of TEFL staff members.

3. Designing the program which included an instructor's manual guide and a student's handouts.

4. Establishing its validity by a panel of TEFL staff members

5. Constructing instruments of the study that included (creative writing test, and a rubric for evaluating students' performance in creative writing).

6. Evaluating the instruments of the study by a panel of TEFL staff members to establish their content validity and reliability.

7. Conducting the pilot study before the real experimentation on twenty-five students to estimate the validity and reliability of the tests.

8. Starting the experimentation on ninety students (from third year English majors).

9. Administering Pre-tests to the study group to establish the equality of participants.

10. Applying the program to the study group.

11. Administering Post-tests to the study group to evaluate the effect of the program used.

12. Analyzing and interpreting the data obtained using appropriate statistical methods.

13. Discussing the results.

14. Reporting recommendations and suggestions for further researches.

\section{Data Analysis}

Data analyses were established by using "t-test", Alfa Cronbach's, Person correlation and Eta-Square using the SPSS program to analyze the obtained data.

\section{Results}

\subsection{Hypothesis 1}

Hypothesis 1 predicted that there would not be a significant statistical difference between mean scores obtained by the study group on the post-test of creative writing skills.

Statistical analysis showed that this hypothesis was not accepted as the t-value (59.093) is significant at (0.01).

This means that there was a significant statistical difference between mean scores obtained by participants of the treatment group on the post-test of creative writing skills.

(Table 4) shows mean scores, standard deviation, 't' value and Eta-squared of the pre-post performance of the treatment group on the creative writing skills test. 
Table 4: Means, Standard Deviation,' $t$ ' value and Eta-squared of the prepost performance of the treatment group on the creative writing skills test

\begin{tabular}{|c|c|c|c|c|c|c|c|}
\hline 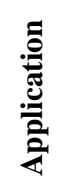 & Z & 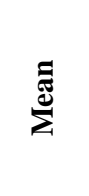 & 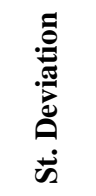 & 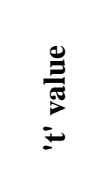 & 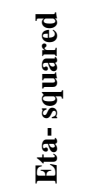 & $\stackrel{\leftrightarrow}{9}$ & $\dot{\ddot{0}}$ \\
\hline $\begin{array}{l}\text { Pre } \\
\text { Post }\end{array}$ & 90 & $\begin{array}{l}61.37 \\
98.42\end{array}$ & $\begin{array}{l}5.296 \\
4.519\end{array}$ & 59.093 & 0.517 & 89 & .000 \\
\hline
\end{tabular}

From the above table, it could be said that there was statistically significant difference between mean scores obtained by the treatment group in the pre-post performance of the creative writing skills test, as't' value (59.093) was significant at (0.01). The effect side of Eta-squared was (0.517) and this value showed the effect of the program on developing creative writing skills.

(Figure 2) shows the study group on the pre-post performance of the creative writing skills test.

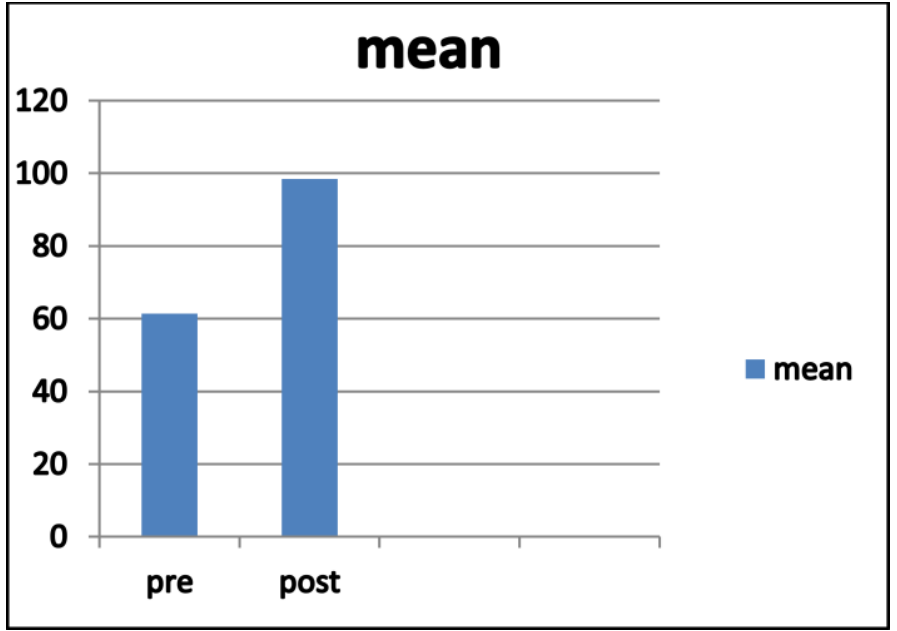

Figure 2: The study group on the pre-post performance of the creative writing skills test

(Table 5) shows mean scores, standard deviation,'t' value and Eta-squared of the pre-post- performance of the study group on each part of the creative writing skills test.

Table 5: Mean scores, Standard Deviation,' $t$ ' Value and Eta-squared of the Pre-Post Performance of the Treatment Group on Each skill of the Creative Writing Skills Test

\begin{tabular}{|c|c|c|c|c|c|c|c|c|c|}
\hline Skills & Application & N. & Mean & St. deviation & 't' value & Eta-squared & D.F. & Sig. & significant \\
\hline \multirow{3}{*}{ Fluency } & Pre & 90 & 13.63 & 2.290 & \multirow{3}{*}{29.087} & \multirow{3}{*}{.442} & \multirow{3}{*}{89} & \multirow{3}{*}{.000} & \multirow{3}{*}{ Significan } \\
\hline & & & & & & & & & \\
\hline & Post & 90 & 23.28 & 2.239 & & & & & \\
\hline \multirow{3}{*}{ Flexibility } & Pre & 90 & 12.37 & 1.738 & \multirow{3}{*}{35.986} & \multirow{3}{*}{.579} & \multirow{3}{*}{89} & \multirow{3}{*}{.000} & \multirow{3}{*}{ Significant } \\
\hline & & & & & & & & & \\
\hline & Post & 90 & 23.47 & 2.193 & & & & & \\
\hline \multirow{2}{*}{ Originality } & Pre & 90 & 11.44 & 2.056 & \multirow[b]{2}{*}{16.422} & \multirow[b]{2}{*}{.631} & \multirow[b]{2}{*}{89} & \multirow[b]{2}{*}{.000} & \multirow[b]{2}{*}{ Significant } \\
\hline & Post & 90 & 16.49 & 2.051 & & & & & \\
\hline \multirow{3}{*}{ Elaboration } & pre & 90 & 11.72 & 1.884 & \multirow{3}{*}{23.665} & \multirow{3}{*}{.364} & \multirow{3}{*}{89} & \multirow{3}{*}{.000} & \multirow{3}{*}{ Significant } \\
\hline & & & & & & & & & \\
\hline & post & 90 & 17.71 & 1.486 & & & & & \\
\hline \multirow{3}{*}{ Total rater 1} & Pre & 90 & 61.38 & 5.296 & \multirow{3}{*}{59.093} & \multirow{3}{*}{0.517} & \multirow{3}{*}{89} & \multirow{3}{*}{.000} & \multirow{3}{*}{ Significant } \\
\hline & & & & & & & & & \\
\hline & Post & 90 & 98.42 & 4.519 & & & & & \\
\hline \multirow{3}{*}{ Total rater 2} & Pre & 90 & 61.17 & 4.694 & \multirow{3}{*}{66.077} & \multirow{3}{*}{0.427} & \multirow{3}{*}{89} & \multirow{3}{*}{.000} & \\
\hline & & & & & & & & & Significant \\
\hline & Post & 90 & 98.71 & 3.672 & & & & & \\
\hline
\end{tabular}


From the above table, it could be said that there was statistically significant difference between mean scores obtained by the treatment group in the pre-post performance of each skill of the creative writing skills test at the significant level (0.01). The effect side of Eta-squared of each part was (0.442) in fluency, (0.579) in flexibility, (0.631) in originality, and (0.364) in elaboration, which showed the effect of the program on developing all creative writing skills.

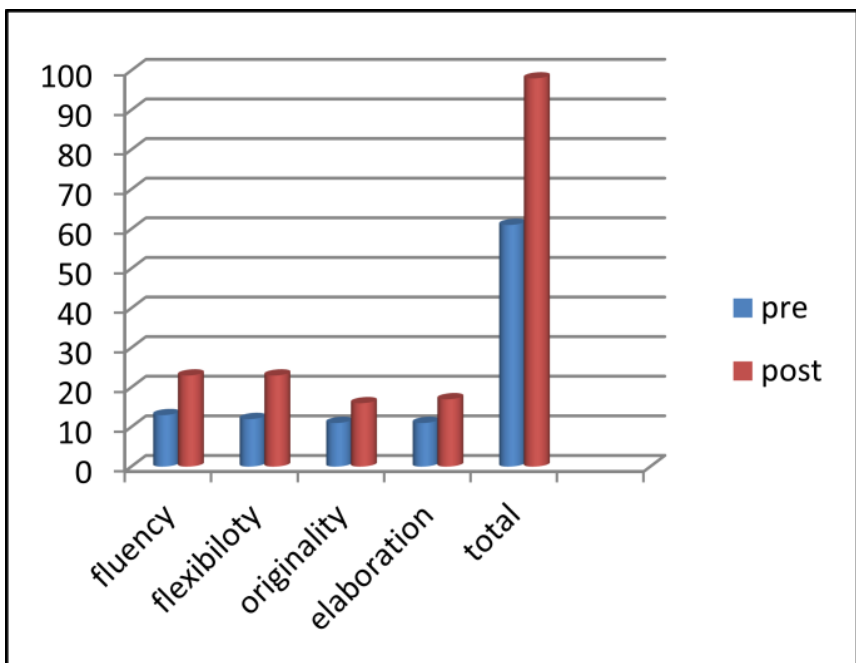

Figure 3: The study group on the pre-post performance of each part of the creative writing skills test

(Figure 3) showed the study group on the pre-post performance of each skill of the creative writing test. The skill that was highly affected was students' originality, then flexibility then, fluency, then elaboration. This result agreed with the results of another study done by [12]

The program dealt with each creative writing skill, first, the program helped students to recognize creative writing skills by presenting knowledge about each skill; its definition and how to apply each skill in writing. Participants were not active in creative writing activities. This appeared on the pre-test of creative writing skills. Therefore the instructor motivated them to participate in creative writing activities by dividing them into groups and using flash cards, they became more active and creative.

The researcher also used some activities based on SCAMPER to motivate students to write creatively. Students managed to write freely in the classroom as they could write with fluency, flexibility, originality and with more details.

It should be noticed that students' overall creative writing skills were developed especially originality as they managed to think out of the box and wrote very wonderful and unique ideas.

It could be concluded that the suggested program based on SCAMPER managed to develop students' creative writing skills.

\section{Challenges}

1. The students were not active to participate in the course, but the researcher gave them an orientation session about the importance of the course not only on their academic life but also in their social life.

\section{Conclusion}

It could be concluded that the program based on SCAMPER strategy managed to develop students' creative writing skills.

\section{Recommendations}

According to the results obtained from the present study, the researcher recommended that:

1- Concentration should be on the higher order thinking skills while designing EFL programs.

2- Using a variety of teaching and learning methods, material and activities to cater for individual differences.

3- EFL teachers at the Ministry of Education should be trained to use SCAMPER strategy in teaching all the language skills not only writing.

4- Faculty of Education Professors should train pre-service EFL teachers on the use of SCAMPER strategy.

5- EFL instructors should train their students on how to use SCAMPER strategy when studying English language.

\section{Suggestions for Further Research}

1- Investigating the effect of using this program with postgraduates.

2- Investigating the effect of using a semantic mapping strategy in developing creative thinking skills.

3- Investigating the effect of using a program based on digital stories on developing creative writing.

4- Conducting studies to investigate the effect of using SCAMPER strategies on developing creative thinking skills and motivation.

\section{References}

[1] Ali, M. A. The Effect of Using E-Learning on Developing the Writing Skills of EFL Secondary School and their attitude towards it. MA thesis in TEFL, Faculty of Education Al-Azhar University; 2007.

[2] Latif, O. The Effect of Training First Year English Majors of the Faculty of Education in integrating Creative Reading and Writing Skills on Their Performance in These Skills. MA thesis in TEFL. Faclty of Education, Minia University; 2007.

[3] De Pereira, S.L. " A step forward in Writing". English Teaching Forum; 1991, Vol.28, No.2,p.21.

[4] Kirby, AHow the Creative Writing Process Works. The Pines Senior Public School: Ontario, Canada; 2003.

[5] Morrissey, F. A. " How can Creative Writing Work". HLT magazine; 1999 Vol 1, no 1 p:1-30.

[6] Abdel-Hamid M. Systems and Creative Thinking. Cairo. (CAPSCU); 2005. [7] Eberle, B. Help! In Solving Problems Creatively at Home and School. Carthage, IL: Good Apple, Inc; 1984.

[8] Glenn, R. SCAMPER for Student Creativity. Education Digest; 1997, vol. 62 (6), pp. 67-68.

[9] Michalko, M. Thinker Toys. A Handbook of Creative Thinking Techniques. Berkeley, Ten Speed Press; 2006.

[10] Fahmy et al. Y Using SCAMPER-based Activities in Teaching Story to Enhance EFL Primary Stage pupils' Speaking Skills (An Exploratory Study). Journal of Research in Curriculum, Instruction and Educational Technology; 2017, Vol. 3 , No. 4 p: 11-33 
[11] Abu zeid, L. Sh. the effectiveness of the SCAMPER strategy or the free production of ideas in the development of creative thinking skills of the students /teacher at Sohag Faculty of Education and improves their attitudes towards creativity. Journal of faculty of Education, Al-Manoufia University; 2017 Vol 32 , no 4, p 240-276

[12] Abu Seif, A. \& Nasr, M. the effect of using SCAMPER strategy on improving Jordanian female tenth grade students creative writing skills, $P h D$ Dissertation, Yarmouk University, Irbid; 2017.

[13] Hussain, M., \& Carignan, A. Fourth Graders Make Inventions Using SCAMPER and Animal Adaptation Ideas. Journal of STEM Arts, Crafts, and Constructions; 2016, vol., 1(2), pp. 48-66.

[14] Abdel-kader, A. M. the effectiveness of SCAMPER model in developing the creative linguistic performance of linguistically gifted pupils at the preparatory stage, international journal for educational researches; 2015, Vol. 37 p 256-301.

[15] Bakr, M. The Efficacy of Some Proposed Activities for Developing Creative Thinking of English Learners at the Preparatory stage (Second year). Doctoral Dissertation, Faculty of Education University of Cairo; 2004.

[16] Hughes, R. Teaching and Researching Speaking. Warlow: Longman; 2002. [17] Ali ،K. S. S. Using a Blended Learning Strategy to enhance Official Language Prep School Students' English Creative Writing Skills. Journal of teaching languages researches, Ain Shams University. Faculty of Education; 2018, Vol 4 p 1-23

[18] Chambers,T. "Creative Writing- Collaborative Stories" ERIC; 1994, pp.4-2. [19] Mc Call, D.M. " Story Completion as a Writing Exercise". English Teaching Forum; 1992, Vol. 11, No. 1. pp.12-11 